\title{
PROCESSO CIVILIZADOR DE PESSOAS COM DEFICIÊNCIA NO BRASIL: DO COLONIAL AMPARO À MODERNA SOCIEDADE INCLUSIVA
}

\section{CIVILIZING PROCESS OF DISABLE PERSON ON BRASIL: FROM SUP- PORT COLONIAL TO THE MODERN INCLUDING SOCIETY.}

\author{
'Janaina Cazini* \\ ${ }^{2}$ Antonio Carlos Frasson** \\ Eloisa Aparecida De Matos ${ }^{* * *}$ \\ João Kovaleski ${ }^{* * * *}$
}

\begin{abstract}
RESUMO
O fomento de novas tecnologias para o sistema produtivo, aliado ao poder do Estado, direciona um novo caminhar no que diz respeito à inclusão de pessoas com deficiência no ambiente produtivo, o qual é repleto de ideologias e de superioridade de grupos sociais, e onde o poder simbólico do Estado se faz presente. Contudo, objetiva-se neste artigo analisar a evolução do processo de inclusão de pessoas com deficiência na sociedade brasileira, com abordagem teórica à luz dos estudos de Norbert Elias, em especial as obras Os estabelecidos e os outsiders e Sociedade dos individuos. Mesmo havendo o aparato legal, questiona-se: o poder emanado pelo Estado brasileiro e pela sociedade industrial conduzem a um processo de inclusão social das pessoas com deficiência? A metodologia utilizada é exploratória, com corpus analítico em fontes de papéis(livros, artigos e jornais). O presente estudo conduz a uma reflexão sobre a historiografia do indivíduo deficiente imbuído de forças do Estado, tecnológicas e sociais.
\end{abstract}

Palavras-chave: Sociedade. Inclusão. Pessoas com deficiência.

\begin{abstract}
The promotion of a new technologies to a productive system joined to the Government power directs to a new way for inclusion of disable people on the producible area. This path filled of ideologies and social groups superiority, that's the symbolical power of the Government made present. This way, this article objective to analyze the evolution of the disable people including process on Brazilian society, with approach the ideas of Norbert Elias', in special, the
\end{abstract}

\footnotetext{
* Bacharel em Administração. Especialista em Planejamento Estratégico e Gestão da Qualidade. Mestranda no Programa de Pós-graduação em Engenharia da Produção - UTFPR/PG.Interlocutora PSAI - Progama SENAI de Ações Inclusiva. E-mail: janainacazini@hotmail.com

** Licenciado em Educação Física. Doutor em Educação. Professor Adjunto da Universidade. Tecnológico Federal do Paraná - Ponta Grossa e do Governo do Estado do Paraná. Professor. Pesquisador do Programa do Programa de Pós-graduação em Engenharia de Produção - UTFPR/Ponta Grossa. E-mail: ancafra@gmail.com

*** Bacharel em Administração. Especialista em Planejamento Estratégico e Gestão da Qualidade. Mestranda no Programa de Pós-graduação em Engenharia da Produção - UTFPR/PG.Interlocutora PSAI - Progama SENAI de Ações Inclusiva.

${ }^{* * * * *}$ Licenciado em Educação Física. Doutor em Educação. Professor Adjunto da Universidade. Tecnológico Federal do Paraná - Ponta Grossa e do Governo do Estado do Paraná. Professor. Pesquisador do Programa do Programa de Pós-graduação em Engenharia de Produção - UTFPR/Ponta Grossa. Professor do Programa de Pós-graduação em Ensino de Ciência e Tecnologia. - UTFPR/ Ponta Grossa.
} 
studies : "The established and the outsiders" and "The individual society" . Even having the legal support, is questioned: The power emanated by the Brazilian Establishment and the industrial society strategies could include the disable person? The methodology used characterized by exploratory with analytical corpus in paper resources. So being, this issues takes to a reflection about the historiography of disable person imbued by the socials and technological Government powers.

Keywords: Society - inclusion.Disable people

\section{Introdução}

Dentro de seu processo evolutivo, a sociedade sempre buscou oferecer ao homem meios adequados e facilitadores do desenvolvimento de suas atividades cotidianas. Isso proporcionou um avanço científico e tecnológico em diversas áreas, que podem ser denominadas de processos sociais. Dentro desses processos sociais, um contingente denominado Pessoas com Deficiências (PcDs), busca, com auxílio das esferas educacionais, governamentais e tecnológicas, um espaço onde possa mostrar que faz parte da sociedade e possui os mesmos direitos.

Os PcDs trazem em sua história um emaranhado de situações no que diz respeito aos aspectos sociais, educacionais e culturais. Ao serem cercados de preconceitos, vistos como indivíduos inferiores, doentes e incapazes, foram excluídos e relegados à marginalidade social por um longo período, o que se evidencia nas teorias e práticas observadas.

No Brasil é possível observar um movimento de inclusão social de PcDs, mas ele é tardio em relação a outros países. Assim, para aproximar e fazer uma incursão nesse universo, o problema a ser analisado assim se configura: como o poder emanado pelo Estado brasileiro e as estratégias da sociedade industrial conduzem a um processo de inclusão social de pessoas com deficiência

Com o foco da investigação centrado em problemas sociais igualmente encontráveis em uma grande variedade de unidades maiores e diferenciadas, os estudos de Elias possibilitam o entendimento em profundidade dos aspectos existentes e, em especial, do nosso objeto de estudo.

\section{Reflexão sobre a in ou exclusão social de pessoas com deficiência}

Elias, ao analisar o processo social que se instala na sociedade, traz para reflexão a análise de um caso em uma pequena comunidade, chamada Wiston Parva, que apresenta contornos apropriados ao que se pretende evidenciar, ou seja as relações sociais existentes, como versa que:

Embora possa variar muito a natureza das fontes de poder em que se fundamentam a superioridade social e o sentimento de superioridade humano do grupo estabelecido em relação a um grupo "de fora", a própria figuração estabelecidos-outsiders mostra, em muitos contextos diferentes, características comuns e constantes. (ELIAS, 2000, p.22).

Para Frasson, Pietrochinski e Schulmeister, no caminho da discriminação social é possível visualizar que

a existência de um grupo considerado como inferior remete necessariamente à existência de um superior que, na maioria das vezes, será privilegiado por alguma condição: social, econômica, intelectual, política, linguística, entre outras (2008, p.3).

Ao ilustrar essa questão, Elias (2000) demonstra a existência de tendências discriminatórias, deixando claro que a estigmatização social é parte de uma visão de alguns, os quais demonstram desapreço, diferença e desprezo pelas outras pessoas, como se elas não fossem indivíduos de direitos iguais.

Os mesmos autores - Frasson, Pietrochinski e Schulmeister (2008, p.3) -, ao abordarem o tema do deficiente, Destacam que:

Tal reflexão parte do princípio de que ainda prevalece um aparato ideológico da elite e do poder que se exercem no espaço social. Espaço este que 
pode ser definido como poder simbólico, permeado pelas relações de poder, constituído por uma sociedade majoritariamente ouvinte, o qual está atrelado intimamente à superioridade de grupos sociais estabelecidos sobre os considerados em situação inferior. (2008, p.3).

Elias (2000) relata claramente que na sociedade dividida em grupos sociais, alguns desses grupos se consideram mais poderosos e melhores que os outros, tendo como instrumento de poder a coesão interna e o controle comunitário. Nesse sentido é possível observar e comparar a sociodinâmica da estigmatização onde o poder gerado pela coesão dos grupos considerados "perfeitos" e pelo controle que possuíam condenava os "não perfeitos" aos maus-tratos e à exclusão da sociedade.

Strijker, ao abordar os preconceitos gerados dentro da sociedade em relação aos pessoas com deficiencia de um modo geral, escreve:

[...] primeiramente torna-se necessário destacar que na sociedade a qual vivenciamos existem inúmeros problemas. Entre estes se destacam: os preconceitos que rejeitam a minoria e todas as formas de diferenças, os ambientes físicos restritivos, os discutíveis padrões e normalidades, os objetos e outros bens fisicamente inacessíveis, os pré-requisitos destinados apenas à maioria aparentemente homogênea, a desinformação sobre deficiência e direitos, as práticas discriminatórias em praticamente todos os setores da atividade humana. (2003, p.167)

\section{Declara ainda que os}

mecanismos que segregam os homens são construídos historicamente pelos próprios homens numa relação dinâmica e histórica. Colocando-se a questão dos portadores de necessidades especiais e seu relacionamento com a sociedade, observa-se que a segregação ainda se faz presente nos dias atuais (2003, p.168).

Carmo (1991), ao discorrer sobre a deficiência, declara: " $\mathrm{Na}$ antiguidade a sociedade traz em sua forma dois tipos de tratamento: um de aceitação e tolerância e outro de menosprezo e eliminação". Citando em sua obra o exemplo das tribos nômades, cujo estilo de vida tornava difícil a aceitação de pessoas com deficiência, as quais eram abandonadas pelo caminho, à própria sorte.
Elias, quando se refere à historicidade de cada indivíduo, declara:

mas não há salto vindo do nada e nenhum mito de origem é necessário para tornar compreensível a relacionabilidade social primeva do indivíduo, sua dependência natural do convívio com outras pessoas. Bastam os fatos que com diretamente vivenciamos. (1994, p.27).

Declara também, que "mesmo dentro de um mesmo grupo, as relações conferidas a duas pessoas e suas histórias individuais nunca são exatamente idênticas. Cada pessoa parte de uma posição única em sua rede de relações e atravessa uma história singular até chegar à morte" (1994, p.27).

As considerações de Elias sobre a sociedade e o indivíduo podem ser exemplificadas claramente pelas pessoas com deficiência, que formam um contingente social singular, onde cada deficiência possui uma particularidade que as torna mais ou menos dependentes.

Mas, devido à evolução tecnológica, principalmente das tecnologias de informação e comunicação, essas diferenças são virtualmente eliminadas. O poder, nesse espaço, é balanceado através das redes sociais de relacionamentos, que fortalecem a ideia de conscientização global na busca da inclusão social das pessoas com deficiência. A dinâmica dos relacionamentos torna-se singular nesse contexto social, buscando-se a erradicação do preconceito e da exclusão social.

\section{Os PcDs dentro do processo histórico bra- sileiro}

Para e refletir sobre o tratamento das pessoas com deficiência no Brasil, inicia-se com o registro da ação de dom Pedro II, que, em 1857, determinou a construção de três organizações destinadas ao amparo das pessoas com deficiencia todas voltadas para a assistência e reabilitação: o Imperial Instituto para cegos e o Instituto para surdos e mudos, fundados em 26 de setembro de 1857, através da Lei n ${ }^{\text {. }}$ 939, e o Asilo dos Inválidos da Pátria, destinado aos ex-combatentes mutilados na guerra em defesa da pátria.

As famílias abastadas, que ansiavam pela integração do deficiente nesse período, pediam que o 
governo tomasse as devidas providências, conforme demonstrado abaixo:

Pedimos ao presidente da província a construção de uma escola para surdos-mudos, pois nossas famílias possuem 4 filhos surdos-mudos, sendo destes 2 do sexo feminino e como serão os supra destituídos de recursos para poder mandar a corte do Império [...] Confiamos em V. Ex. como um grande protetor da instrução [...] (Carta ao presidente da província, 1884, Arquivo Público do Paraná).

Esse anseio familiar em amparar seus entes com deficiência foi essencial para introduzir no Brasil uma tecnologia que auxiliaria os deficientes visuais, o sistema Braille. Este fato é visível quando temos que:

José Álvares de Azevedo, filho de uma família abastada, e tendo nascido cego teve especial dedicação por parte dos seus pais que através de um amigo da família, souberam que existia, na França, uma escola para atender a alunos cegos e onde o menino poderia estudar, depois de seis anos ininterruptos, dedicando-se inteiramente aos estudos, voltou ao Brasil em 1851 e trouxe em sua bagagem o Sistema Braille e o ideal de poder criar uma escola para cegos, semelhante ao Instituto Real dos Jovens Cegos de Paris. [...] A demonstração de como uma pessoa cega podia escrever e ler correntemente, pelo Sistema Braille, deixou o Imperador interessado e sensibilizado e imediatamente concordou com a ideia e a proposta de se criar uma escola para cegos, semelhante à escola de Paris, no Rio de Janeiro, e delegou plenos poderes ao jovem professor e ao seu médico Dr. Sigaud, para desenvolverem o processo para a criação dessa escola. Em 1857 através a inauguração do Imperial Instituto para Cegos. (www.netsaber. com.br/biografias).

Fazendo uma análise desse período à luz de Elias (2000), observa-se as relações de poder entre estabelecidos, as pessoas "normais" e os "outsiders", pessoas com deficiências, pelas características de carisma e estigma que se assemelham .

Dunning (2005), ao analisar as características de carisma e estigma que moldam as relações de poder, declara

Um exemplo significativo se verifica na relação entre os chamados portadores de necessidades especiais [...] quando propõem a identificação do outro grupo multifacetado, denominado deficientes, ou x, ou y, ou z. (p.23).
Nesse contexto, observa-se que as relações de poder para com os PcDs advém do elevado carisma e proteção das famílias e do estigma assistencialista da Igreja e do governo.

Um pouco adiante nesta história temos o discurso do ministro da Educação, enviado para o Congresso Nacional sobre o Bem-Estar das Pessoas Deficientes, em 1974, o que demonstra a intenção do Estado em mudar a visão da sociedade para com os PcDs, passando de amparo e assistencialismo carismático para uma reabilitação que iria contribuir para a sociedade.

Cada cego integrado, pessoal e profissionalmente, no meio normal, torna-se elemento útil e produtivo. As técnicas, processos, aparelhos, invenções e iniciativas que se desenvolvam em prol do deficiente, em qualquer setor do conhecimento humano, redundam em bem para todos." ..."a reabilitação dos deficientes não é apenas promoção dos limitados, pois ela reabilita, promove e recupera toda a sociedade, a globalidade inteira dos homens e dos povos. (O ESTADO DO PARANÁ, 1974).

A mobilização de setores políticos brasileiros interessados na questão dos direitos das pessoas com deficiência iniciou-se na década de 1980, quando entrou na pauta dos governos a necessidade de criação e implementação de políticas públicas voltadas para esse contingente.

Os esforços para inclusão foram promovidos inicialmente por organizações internacionais. Em 1978, Norman Acton, secretário geral da reabilitação internacional, consultor da ONU e UNICEF para assuntos de pessoas incapacitadas, destacava que:

O governo deve assumir a responsabilidade maior na criação e desenvolvimento de serviços de reabilitação para todos os portadores de incapacidades físicas e mentais devendo ainda dar educação gratuita às pessoas ou a sua família.

A comunidade em geral deve financiar através dos impostos e outros meios a educação especial e a integração no sistema educacional geral.

Organizações voluntárias prestam serviços educacionais especiais. Como organizações de pais e entidades privadas, muitas vezes, são as primeiras a tomar consciência dos problemas existentes 
quando faltam serviços especiais, prestando os primeiros serviços e persuadindo os governos.

(O CORREIO, maio de 1974).

Observa-se também os movimentos sociais e educacionais que impulsionaram as ações de inclusão de PcDs a partir de escolas particulares, como a Mercedes Stresser e a Apae, que buscavam, através de trabalhos manuais, formas produtivas de integrá-los na sociedade.

A escola particular Mercedes Stresser, da cidade de Curitiba, possui os projetos Oficina Pedagógica e Oficina protegida, para o treinamento e desenvolvimento profissional de jovens excepcionais [...] (CORREIO DE NOTÍCIAS, 1984).

Apae (Associação de Pais e Amigos dos Excepcionais), em parceria com pais de deficientes formam núcleos de educação especial onde os próprios pais se reúnem e desenvolvem atividades em grupo com seus filhos. O programa comunitário atende 150 famílias, devido à falta de vaga nas instituições públicas (FOLHA DE S.PAULO, 1988).

Quase uma década depois das ações educacionais para inclusão de PcDs desenvolvidas pelas famílias e organizações filantrópicas, as escolas regulares começaram a responsabilizar-se pelo processo de inserção.

Um dos motivos da falta de estrutura para atender os deficientes é que, até 1995, praticamente não havia ações governamentais na área. Quem se ocupava da educação de deficientes eram instituições filantrópicas, como Apae e o Instituto Pestalozzi, que sobreviviam de doações e, por isso, tinham dificuldades de atender a todas as crianças e jovens de idade escolar portadoras de deficiência. A partir de 1996, com a implantação da Lei de Diretrizes e Bases da Educação, Estados e Municípios assumiram a responsabilidade de educar essas crianças (FOLHA DE S.PAULO, 1998).

Ao refletir sobre a inclusão dos PcDs entende-se que a mesma deve se iniciar no meio educacional e que apenas as ações filantrópicas não conseguem atender todo o contingente e eliminar as barreiras da reclusão, por isso faz-se necessário a intervenção de outras esferas.
Encontramos em Elias a explicação de que fatores externos aos PcDs contribuem para a inclusão e exclusão social:

Cada pessoa singular está realmente presa; está por viver em permanente dependência funcional de outras; ela é um elo nas cadeias que ligam outras pessoas, assim como todas as demais, direta ou indiretamente, são elos nas cadeias que as prendem. Essas cadeias não são visíveis e tangíveis, como grilhões de ferro. São mais elásticas, mais variáveis, mais mutáveis, porém não menos reais, e decerto não menos fortes. E é a essa rede de funções que as pessoas desempenham umas em relação a outras, a ela e a nada mais, que chamamos "sociedade". (ELIAS, 1994, p.21).

Para que o caminhar de inclusão social dos PcDs não se torne moroso na sociedade atual, faz-se necessária a intervenção das esferas tecnológicas e estatais, além do fortalecimento do elo de ligação entre a educação e a conscientização.

\section{A legislação brasileira em relação aos PcDs}

O Estado brasileiro, com o intuito de bem prover e atender aos PcDs, aprovou leis que buscaram diminuir a discriminação e aumentar a inclusão, tanto social como profissional:

\section{5 - Lei no 939 - Dom Pedro II}

Criação do Imperial Instituto para cegos e do Instituto para surdos e mudos.

1978 - Emenda 12 à Constituição Federal Deputado Federal Thalles Ramalho

Para reabilitação do deficiente através de tratamento, reintegração à vida econômica e proibição da discriminação na contratação de trabalho.

\section{8 - Constituição Federal}

Art. 203 - Todas as pessoas com deficiências que comprovem não possuir meios de se sustentarem ou de serem sustentados por familiares, receberam um salário mínimo mensal.

\section{9 - Lei $\mathbf{n}^{0} 7.853$}

Criação da Corde - Coordenadoria Nacional para Integração da Pessoa Portadora de Deficiência e obrigatoriedade da inclusão de questões 
específicas sobre a população com deficiências nos censos nacionais.

\section{1 - Lei $n^{0} 8.213$}

Obriga empresas com mais de 100 funcionários a preencherem de 2 a $5 \%$ do seu quadro funcional com pessoas com deficiência.

\section{6 - Lei de Diretrizes e Bases da Educação}

Estados e municípios possuem a obrigatoriedade de incluir crianças com deficiência nas escolas públicas.

\section{9 - Decreto no 3.298}

Convenciona a deficiência e descreve todos os tipos de deficiências.

\section{1 - Decreto $n^{0} 3.956$}

Promulga a Convenção Interamericana para Eliminação de Todas as Formas de discriminação Contra as Pessoas com Deficiência.

\section{4 - Decreto $n^{0} 5.296$}

Regulamenta as leis de acessibilidade em prédios e órgãos públicos e particulares.

\section{4 - Decreto Federal $n^{0} \mathbf{5 . 2 6 9}$}

Determina que os estabelecimentos de ensino proporcionem condições de acesso e utilização de todos os seus ambientes para Pessoas com Deficiência.

\section{7 - Decreto no 6.214}

A pessoa com deficiência integrada no ambiente de trabalho que por ventura perde o emprego voltará a receber o benefício do governo.

Ao analisar os ditames legais implantados no Brasil, observa-se que há uma evolução no tratamento das pessoas com deficiência, desde a criação do Imperial Instituto para cegos e do Instituto para surdos e mudos até a Constituição Federal de 1988, que tratam do amparo dos PcDs, passando pelas leis de acessibilidade e a obrigatoriedade de inclusão em ambientes produtivos, as quais buscaram promover a inclusão social e profissional dessas pessoas.

Os recortes jornalísticos a seguir destacam duas situações geradas pela Lei $\mathrm{n}^{\circ}$ 8.213/91, a qual exige que empresas que possuam acima de
100 funcionários contratem 2 a $5 \%$ de pessoas com deficiência. O primeiro revela as vantagens da contratação e o segundo o descaso das empresas perante a lei.

Avon: Contratou 24 deficientes (auditivos, visão e mental) alocou-os numa seção da fábrica onde os funcionários tem de ler de pressa, uma lista de pedidos, apanha os itens em pequenos compartimentos e distribui-os em caixas de papelão que passam pela esteira. "A margem de erro nunca foi tão pequena chegando próximo de zero" espanta-se o consultor de R.H da Avon (GAZETA DO POVO, 1995).

Dez anos após a criação da Lei 8.231/91, que obriga as empresas com mais de 100 empregados a terem em seus quadros de $2 \%$ a $5 \%$ de portadores de deficiência, o presidente da Associação dos Deficientes Físicos do Paraná (ADFP), desabafa que o preconceito e a dificuldade de acesso a educação de qualidade confinam os deficientes a cargos menos importantes. As empresas alegam que não cumprem a legislação por dois motivos. O primeiro é que desconhecem o decreto. O segundo é que teriam que demitir outros empregados para colocá-la em prática (GAZETA DO POVO, novembro de 2001).

A presença do Estado na questão dos PcDs estimulou a reflexão acerca da importância de sua inserção para o desenvolvimento das pessoas com deficiência no Brasil. Proporcionando um entendimento da transformação social que inicialmente era de amparo para a reabilitação e inserção social

\section{A sociedade inclusiva}

Ao abordarmos a sociedade inclusiva temos em Santarosa um dos autores que nos possibilitam uma visão adequada do tema ao declarar que

uma sociedade inclusiva é aquela capaz de contemplar, sempre, todas as condições humanas, encontrando meios para que cada cidadão, do mais privilegiado ao mais comprometido, exerça o direito de contribuir com seu melhor talento para o bem comum. (SANTAROSA, 2003, p.20).

O ideal social, descrito por Santarosa, pode ter iniciado a partir do cumprimento da Lei $\mathrm{n}^{\circ} 7.853 / 89$, que exigiu a inclusão de mais 
informações na pesquisa do IBGE (Instituto Brasileiro de Geografia e Estatística) sobre as pessoas com deficiência. Contudo, somente no censo realizado em 2003 pelo IBGE foi possível mostrar à sociedade e ao Estado a realidade das pessoas com deficiência. Um total de 24,5 milhões de pessoas declararam-se portadoras de algum tipo de deficiência, o equivalente a $14,5 \%$ da população brasileira, sendo: visual: $48,10 \%$; motora: $4,10 \%$; auditiva: 16,70\%; mental: $8,30 \%$ e física: $22,90 \%$.

Com todo o aparato legal descrito no tópico anterior e as informações sobre esse contingente, inicia-se um movimento mais efetivo de inclusão social das pessoas com deficiência. A tecnologia, mais desenvolvida nesse período, também se torna uma esfera que irá contribuir para o processo de inclusão de pessoas com deficiência.

A evolução ocorrida com a tecnologia voltada para as pessoas com deficiência iniciou-se através das pesquisas em universidades, para a construção de equipamentos que auxiliassem no tratamento e locomoção dos PcDs, conforme as noticias dos jornais da época:

Universidades estão desarquivando teses antigas sobre minimizar os problemas dos "diferentes" e oferecendo às indústrias, para posterior comercialização, como também sugestões para enfrentar dificuldades em todos os tipos de construções. Assim surgem as cadeiras de banho desmontáveis; os orelhões baixos, cadeiras de rodas motorizadas, rampas de acesso a prédios, tecnologias especial para os diferentes (GAZETA DO POVO, 1982).

IBM esta lançando no mercado brasileiro a partir de junho, a versão em português de seu avançado software com comando de voz Home Page Reader. O novo produto é específico para atender as necessidades de deficientes visuais que queiram navegar na $\mathrm{Web}$, incluindo operações como compra, venda, troca de produtos ou até mesmo realizar recursos on line. Via Voice e Speech Viewer via sintetizador de voz Outloud da IBM são 3.0 é de $\mathrm{R} \$ 344,00$ (GAZETA DO POVO, 2001).

Tais inovações tecnológicas são conhecidas por tecnologias sociais. Segundo Cazini (2009), as tecnologias sociais se caracterizam dessa forma por contribuírem em algum momento para a inclusão social e a melhoria da qualidade de vida de toda a população, mas existe um subgrupo de tecnologias sociais desenvolvidas para atender a um contingente específico de pessoas, com o objetivo de ampliar suas habilidades. São as tecnologias assistivas.

A tecnologia assistiva é qualquer instrumento, estratégia, serviço e prática utilizados por pessoa com deficiência e pessoas idosas. Instrumentos especialmente produzidos com o intuito de prevenir, compensar, aliviar ou neutralizar uma deficiência, incapacidade ou desvantagem visando uma autonomia e melhora na qualidade de vida dos indivíduos (ONU, 1995). Dentre esses recursos existem os softwares de acessibilidade aos ambientes digitais voltados para as pessoas com deficiência visual, que possuem funções como: ampliadores de tela para as pessoas de baixa visão, leitores de tela e sincronizadores de voz para os cegos (UNESCO, 2008).

\section{Considerações finais}

O presente artigo estimulou a reflexão acerca da importância do Estado no desenvolvimento civilizador da sociedade para com as pessoas com deficiência no Brasil e evidenciou um processo não planejado de amparo à reabilitação e à inserção social, num despertar para a sociedade inclusiva.

Mas as oportunidades entre as quais uma pessoa se vê forçada a escolher não são, em si mesmas, criadas por essa pessoa; são prescritas e limitadas pela estrutura específica de sua sociedade e pela natureza das funções que as pessoas exercem dentro dela.

É evidente que as esferas da educação e da tecnologia, também possuem importante contribuição para o processo de civilização e inclusão de pessoas com deficiência no Brasil, pois moldaram os acessos dos indivíduo com deficiência: tornando-os reabilitado e produtivo; e os indivíduo sem deficiência: conscientizado e habilitado a conviver e trabalhar com todas as diferenças.

Ao analisar os jornais e corpus analíticos do período histórico, concluiu-se que o poder emanado do Estado, as tecnologias e a educação, juntos e integrados, são fenômenos que integram e incluem social e profissionalmente as pessoas com deficiência. 


\section{Referencias}

ANTUNES, R. Crisis capitalista contemporánea y las transformaciones en el mundo del trabajo. In: Capacitaçao em serviço social e politica social: Modulo 1. Brasilia: CEAD, 1999.

ARENDT, H. Los orígenes del totalitarismo. Madrid: Alianza, 1951

BAUMAN, Z. Modernidade e ambivalencia. Rio de Janeiro: Jorge Zahar, 1999.

BOBBIO, N. El futuro de la democracia. 2.ed. México: FCE, 1997.

COTTA, M. "Parlamentos y Representación” en manual de ciencia política. Salamanca: Alianza Universidad,1988.

DAHL, R. La democracia y sus críticos. Barcelona: Paidós, 1992.

FOUCAULT, M. La ética del cuidado de si como practica de libertad. In: Coleçao ditos \& escritos, 5. Brasil: Política Forense Universitaria, 1988.

Deux essais sur el sujet et le pouvoir. In : DREYFUS H.; RAIBOW, P. Michel Foucault: un parcours philosophique. Francia, Gallimard, 1984.

FRAGA. P. C. P. et al. Jovens en tempo real. São Paulo: DP\&A editora, 2003.

FRANCO, Y. Subjetividad: lo que el mercado se llevó: una perspectiva desde el pensamiento de Cornelius Castoriadis. Disponible en: <www.magma-net.com.ar/subjetividad. htm>.

FREUD, S. El yo y el ello. Amorrortu, v.18, 1923.

El desactivamiento del complejo de Edipo. Amorrortu, v.19, 1924.

GARGARELLA, R. La crisis de la representación política. México: Fontamara, 1997.

HELD, D. Modelos de democracia. México: Alianza Editorial, 1992.

KLEIN, A. Adolescentes sin adolescência: formas de construcción de la subjetividad adolescente desde el contexto neoliberal. Uruguay: Psicolibros, 2006.

KYMLICKA, W.; NORMAN, W. El retorno del ciudadano: una revisión de la producción reciente en teoría de la ciudadanía. Revista de estudios sobre el Estado y la Sociedad, n.3, Octubre, Paidós, España, p.5-40, 1997.

LEWKOWICZ, I. Pensar sin Estado: la subjetividad en la era de la fluidez, Argentina: Paidós, 2004.

MACEDO, S. Diversity and distrust: civic education in a multicultural democracy Cambridge: Harvard University Press, 2000. Paperback March 2003.
MADISON J. "Federalist 57" y "Federalist 10" En: HAMILTON, A., MADISON, J.; JAY, J. The federalist papers. Nueva York: Penguin, 1961.

MANIN, B. The principles of representative government. Cambridge, Cambridge University Press, 1997.

MARSHALL, T. Ciudadanía, clase social y status. Brasil: Labor, 1967.

MILL, J. S. Consideraciones sobre el gobierno representative. México, Gernika, 1991.

PITIKIN, H. The concept of representation. Berkley: University of California Press, 1984.

PUGET, J.; KAES, R. Violencia de estado y psicoanálisis. Argentina: Centro Editor de América Latina, 1991.

SADER, E.; GENTILI, P. La trama del neoliberalismo: mercado, crisis y exclusión social. Argentina: Universitaria de Buenos Aires, 1999.

SARTORI, G. Teoría de la democracia: el debate contemporâneo. México: Alianza Universidad, 2000a.

Teoría de la democracia: los problemas clásicos. México: Alianza Universidad, 2000b.

TILLY, C. Democracy. Cambridge: Cambridge University Press, 2007.

Recebido em: 15/11/2011 Aprovado para publicação em: 24/04/2012 